\title{
Interaction For Academics In The Industrial World: The U.S. And Japan
}

\section{Duncan Moore}

Duncan T. Moore, "Interaction For Academics In The Industrial World: The U. S. And Japan," Proc. SPIE 0978, 1988 Intl Conf on Education in Optics, (27 April 1989); doi: 10.1117/12.948594

Event: 32nd Annual International Technical Symposium on Optical and United States 
Interaction for Academics in the Industrial World: The U.S. and Japan

\author{
Duncan T. Moore \\ The University of Rochester - The Institute of Optics \\ Rochester, New York 14627
}

\begin{abstract}
Interaction of the industrial and academic world is of course a very old problem. The relative roles of each organization and the education of the next generation of scientists has long been debated. However, in the last ten years, there has been a substantial change in the interaction and the expectations of each group. The principal reason for these changes have to do with pure economics. As the cost of "big science" has increased. The need for more resources at universities to train students has increased and the need for highly trained students, who work as teams rather than as individual scientists, has become more important. No longer is corporate research done exclusively by the single scientist or engineer working in their laboratory for long periods of time to come up with the "Eureka" solution. At universities, the tenure system tends to require an individual to develop his or her own research topic. The cost of developing new topics has increased enormously. In this paper, the interaction of industry and the academic world are reviewed from the viewpoint of the academic individual. While I have had industrial experience, it was not as great as others who have written on the subject. The main topics are, 1) what drives the need for so much money in the university community, 2) assuming there is a need, what are the sources of those funds, 3) what role should American and foreign companies play in educating and sponsoring research at universities, 4) what should be the expectations of the university community and the industrial world, 5) what are possible formats for such an interaction, and finally, 6) what are the dangers to the universities and to the United States economy in the long run by such interactions.

\section{NEED FOR MONEY}

While the title of this section would indicate that an MBA had written it, unfortunately, the world of managing an academic department has become closer to the management of an industrial group. This has had a number of bad effects. One, it has made the role of department chairman a less desirable position than it was twenty years ago and it has brought a strong component of business into the academic world. While academics would argue that this is a terrible situation, the industrial world on the other hand, would argue that this is exactly what should be happening so that students and faculty are more oriented towards the real cost of doing research and developing products. It is interesting to note that department chairman (directors) tended to stay for a long period of time in that position in the 1920's, 30's 40's and even 50's. Typically, a department chairman/director turns over every three to six years. As best as I can tell, it was more fun to be director twenty years ago.
\end{abstract}


There are two main factors that seem to be driving the need for money at academic institutions. One of these is independent of the field of research, that is, the cost of "big science", whether it would be at the industrial location or in the academic department. The second factor is somewhat unique to optics and a few other highly specialized areas, i.e., the tremendous growth that has occurred in these areas creating enormous pressure on our academic institutions. Both of these can be viewed as an opportunity if one is equally willing to understand the frustrations.

In the first case, independent of what area of engineering or hard science involved, the costs of doing research are increasing enormously. This is principally driven by the cost of the capital equipment involved in doing the new science and the cost of salaries for first rate Ph.D. students. One can argue that the problems are tougher today than they were 20 years ago, and certainly in more mature areas (ones in which significant amounts of research has already been conducted) this is certainly true. In general, I am unsure that there are not problems that can be solved by the individual scientist working alone in his or her own laboratory, but the common conception is that this is the exception rather than the rule today. Whether we accept this or not can be the subject of another debate. It is clear that the cost of capital equipment today is significantly higher than it was 15 years ago. The type of capital equipment necessary to conduct certain types of research is more expensive. The recent installation of the Molecular Beam Epitaxy (MBE) facility at the University of Rochester, will cost us something in excess of one million dollars, exclusive of any salaries or supplies for the scientists who conduct the research. This type of expenditure 15 years ago could not have been considered. Beyond that, the cost of operating such a facility will cost between $\$ 150,000$ to $\$ 200,000$ per year not including the cost of the scientists and the graduate students who will be working on the project. This creates a need for a large cash flow for this one project alone. Even if universities resisted the temptation to go into "big science" or "expensive science", there would still be enormous pressure from industry to educate our students in the latest techniques and methods of conducting first rate research. This scenario of a big research program cannot be avoided if we are to maintain a first rate research component in our society.

The biggest component of the change in cost is that of salaries. I have divided this out into those of faculty and those of students. Since I joined the faculty in 1974, I will use the salaries over the last 14 years as a baseline. In 1974 a typical (if I be typical) faculty member received a starting salary of $\$ 13,000$ for a nine month period. I was guaranteed two months of summer support if I was unable to raise it on my own contract to give a total 12 month compensation of $\$ 15,900$ (it was difficult to raise 3 months of summer support at that time). At that same time, the starting salaries I was offered averaged about $\$ 22,000$. Therefore, as a baseline, I received about $72 \%$ of the salary at the University of Rochester that I would have received had I gone to the industrial world. In 1988, the starting salaries at the University for a fresh Ph.D. with little or no experience is approximately $\$ 38,000$ for a nine month period. Assuming that we continue to guarantee two months of summer support (which we have continued to do) this brings the 12 month salary to $\$ 46,400$. Since the statistics on this are rather small, I have looked at the salaries of the graduating Ph.D.'s this year and 
found that they range from $\$ 48,000$ to $\$ 55,000$. If we assume that the average is about the typical student at the University is receiving about $87 \%$ of what he or she would have received in the industrial world. If a faculty member were to do 10 to 15 days of consulting per year, the two salaries would be exactly equivalent. In 1974, I would have had to have done between 20 and 30 days of consulting in order to make the two equivalent. To obtain a total salary for all faculty members, assume the average salary of faculty members is one and one half times the starting salary. In 1974, (while we did not have all of our slots filled) I believe that we had 15 faculty slots that could have been filled and therefore the budget line for that part of it would have been $\$ 357,750$. In 1988, for 15 faculty members, the total cost is $\$ 1,000,044$. Of course, this does not include the cost of benefits and overhead that are attributive to faculty salaries in either event.

The more telling part of it is the cost of supporting graduate students. In 1974, the stipend was $\$ 2,600$ per year plus the cost of tuition which was $\$ 3,275$. At that time, there were 33 doctoral students in the program at Rochester representing a total cost of $\$ 85,800$. The total cost of tuition for those same students was $\$ 78,600$. In 1988 the average stipend for Ph.D. students is $\$ 13,500$. We have 86 Ph.D. students in residence for a total cost of approximately $\$ 1,000,160$. The tuition for this coming year will be approximately $\$ 12,000$, but of this total only about 45 students will have a tuition obligation resulting in a cost of $\$ 540,000$. In 1974 , the total cost for the graduate students was $\$ 164,400$ while in 1988 the total was $\$ 1,701,000$. When you combine the student costs plus the faculty salaries, I find in 1974 the cost of salaries for the faculty and students was approximately $\$ 600,000$ while in 1988 it was almost $\$ 3,000,000$. Of course, none of these figures include the overhead costs that are associated with the cost of doing research or teaching. Including them would only further illustrate the need for increasing the cash flow of academic departments today.

By comparison, in Japan, the cost of faculty salaries are substantially lower. While I do not have baseline numbers for 1974, it is interesting that the cost of a salary in 1984 was between 5 and 7 million yen. In 1984 the yen/dollar ratio was 240 resulting in a salary of approximately $\$ 25,000$. In 1988 the yen is 130 to the dollar and assuming that there were no salary increases during that time, the equivalent-cost today would be $\$ 46,150$. Remember, the equivalent 11 month salary in the $U$. $S$. for the average professor is about $\$ 69,000$. A more interesting feature is that the ratio between industrial salaries and academic salaries is almost one. In many cases, the faculty receive a slightly higher starting salary than they would in industry. On the downside of it, at most Japanese universities, which are public, the faculty is not allowed to consult as they are public employees. While there are certain "arrangements" that can be made between industry and individual faculty members, it is difficult to determine the amount. A more startling effect comes when one considers the cost of educating graduate students there. While there are real costs associated with education, the students are expected to pay not only their tuition, but their own living expenses. The system is very much like the system for law schools and medical schools in the United States, and completely different from that of engineering and the hard sciences. 
Therefore, the cost for having a faculty of 15 people and an infinite number of graduate students in Japan is about $\$ 700,000$ or about one quarter of the cost in the United States. This creates a significantly lower cash need among Japanese universities than in American ones. This is one of the reasons there is much less sponsored research at Japanese universities and certainly the growth of "centers" has not started there.

While the cost of salaries is an important component of maintaining an organization, the recruiting of young faculty members today is becoming more expensive as start-up funds are required in order to be sure that the young faculty members are successful. It makes very little sense to bring in a young faculty member and then say, "go get your own contract money". Typically, they have no experience in this area and they will spend the first three to five years trying to generate any sort of contract support. It is far better for universities to understand that the cost of start-up equipment relative to their salaries is not very large. Start-up funds can range from as little as $\$ 20,000$ for a theorist who may only need a work station today, to $\$ 1,000,000$. if one is entering a new field as we did in MBE. For a typical experimentalist, the startup funds will be between $\$ 50,000$ and $\$ 150,000$. However, this is the real cost of doing business and should be recognized by both the university and industry. If we want to have a first rate university, we have to provide facilities for these young faculty members to initiate their research. They are under enormous pressure to publish new work as early in their career as possible, in order to achieve tenure. The role of raising contract funds should be left to those people who have been around the system for a while and have gone through the intellectual hoops of the tenure system.

There is a second problem that I believe is unique to optics and a few other very specialized fields, that is, the number or students who want to go into the field. In figure one, the number of undergraduate students at the University of Rochester is plotted as a function of time. In 1970 when the chart was begun under Brian Thompson's leadership, there were approximately 29 students in our total undergraduate population. We were graduating between 4 and 8 students per year. In 1988, we will have approximately 300 enrolled in the optics program. In the last two years, we graduated 96 students in 1987 and 83 students in 1988. At steady state now, we will be graduating between 70 and 85 students per year. Students have realized that optics is a hot topic. This is reflected further when we look at figure two, which is our graduate population. The graduate population is capped by the department, but it has shown steady growth over this period of time. Two reasons have contributed to this; namely, the large number of students coming to the department and wanting to enter optics and the fact that it has taken longer for students to finish their Ph.D. dissertations. There are a number of reasons for this which are not always shared by my colleagues and certainly not by the students. Among them are the fact that stipends are now so high that there is not the financial incentive there once was to leave the university as quickly as possible. Second, each faculty member is carrying more students than he or she was 15 years ago and the time allotted to each student must go down. Therefore, it is more natural for a student 
to go along a path for a longer period of time without being redirected as they might have done 15 years ago. Three, there is little incentive on the faculty members part to graduate the student because after the student has been here 4 or 5 years, the student is an inexpensive post-doctoral fellow. The students generate an enormous amount of papers per year and that certainly helps the output of the faculty and the department itself. Unfortunately, this is a crisis with which nobody wants to deal. It is not in the best interest of the students to see a decrease in stipends over time and it is not of best interest to the faculty to see that happen. Unfortunately, this is one of the key problems that I will have to wrestle with in the next year. The demand for the program has increased and it is interesting to note in figure (3) that the distribution of students is very highly U. S. oriented. This is true both in our application pool and in our acceptance pool. It should be noted that the total number of applicants for this year, which was 142 for the Ph.D. program and 82 for the masters program, did not reflect all of the people who sent in applications. In fact, the University of Rochester uses a two part application for foreign students (only those that pass the first part may apply for regular admission).

Clearly from this part of the paper, barring a change in our educational system, more money needs to be raised. We could consider a different system by which students pay for their own education, which would cut our costs enormously. However, we cannot afford to cut the cost of faculty salaries. I am a firm believer that if you want to have a first rate department, you must pay first rate salaries. If you want to have first rate graduate students, you must pay first rate stipends. The concept that if you have many applicants you can pay less because the market forces will allow that, is a short-term scenario which will have significant long-term negative effects.

\section{SOURCES}

There are basically five sources of money. The first is gifts from alumni companies and foundations. This is really not the topic of this meeting and is not a significant source of funds for individual departments. While it may be a significant source of funds for universities as a whole, little has been done to make alumni aware of their "responsibilities" to be good alumni of the department, and to give generously and often. This is something of which we need to be more aware. Certainly law schools, medical schools, and music schools live comfortably off their alumni. We in engineering have not created this culture, but may in fact be a good source of money in the long-term. It is not inconceivable that we should be looking at departmental endowments as do these other specialized schools to allow for the "rainy" day problem. This however, has to be viewed as a 20 to 30 year long-term development campaign and should not be viewed as something that will help in the short-term. The second source of funds is federal contracts. Federal contracting, depending upon who you are talking to, is either going up or going down. Six to one money is either going up or going down, six/two money is either going up or going down for university work. Clearly, there is some opportunity to expand, especially in the optics area, as optics is becoming more popular through the designation of the Photonics Center at Rome Air 
Development Command and the general recognition through various publicly discussed issues that involve optics and lasers.

The third area of support is that of state programs. States have become much more interested in the role of universities and the industrial world. In that line, they have designated certain specialized areas of engineering to receive significant amounts of money. Many States have these programs and the leaders are probably Michigan, California and New York. These programs have actually been copied in other parts of the world. (France currently has a program that is very much like the program in New York State.) This program will be discussed a little bit further but one has to remember that the State's motivation for such a program is economic development, (how many jobs are going to be formed as a result of putting this money into the system).

The fourth source of money is increased university resources. If you are a private university, this means you need to somehow make the case that your department is more important than some other department to the Board of Trustees. If you are a public university, you must make the same argument through the Chancellor to the State Legislature. This results in a tremendous amount of lobbying both locally and at the State Capitol. The pie is only so big. It is a scarey prospect to recognize that tuition revenue is becoming a smaller and smaller fraction of the cost of operating major universities today. More and more universities are relying on the indirect cost to run the university, which means they are more and more susceptible to fluctuations in Washington and in State Capitols. This further means there is more pressure on individual faculties to have more funded research which will generate more indirect recovery. This is a danger that many universities face.

The final source of funds is that of the industrial sector. While industry had long been viewed philanthropically for many years by universities, it is only recently that individual departments started to work significantly with our industrial colleagues.

\section{INDUSTRIAL AND STATE SUPPORTED PROGRAMS}

While there is a temptation to try to separate state funded from industrial ones, this is not as easy as one would first think. In most states, the support of the State Capitol and the Legislature is tied to matching arrangements with the industrial sector. This comes about from the philosophy that the legislators want to be assured that the money being spent is somehow relevant to the state needs. The details of this vary from state to state. It is important to remember that the state's motivation is purely one of economic development. How is this going to create more jobs? There are various algorithms used to dictate how many jobs need to be created per unit dollar invested. Independent of that, one must show, in order to maintain the program over an extended period of time, the program is contributing to job formation within your region. The pressures now are certainly to show that small businesses have been formed. This is a more difficult problem because the people who are sponsoring it are 
the large corporations. While they may feel that small businesses are important to their local community, they want to know exactly what their benefit is after giving this money. The corporations view their support from two standpoints. First, that it is costeffective research. While I have argued earlier in this paper the cost of education at universities is very large, the cost of doing that same research at an industrial site would be significantly higher. While not all companies submit to the theory that universities can do cost-effective research (the theory is you get what you pay for) certainly a number of corporations believe this is a way of studying a number of areas without having to invest large amounts of resource. The second reason is the expansion of their technology base. No major corporation would give up their fundamental research in the areas of their main line business. However, it is impossible now for any major corporation to maintain a research program in all areas of science, and further, even in all areas of optics. This provides universities with opportunities to complement the research efforts of major corporations.

The final component in these state programs is, of course, the people at the department level who must conduct the research. The advantage of state money over federal money is that it tends to be less restricted. The states tend to be less bureaucratic than the federal government. They are relatively new at the funding of research and engineering and, therefore, do not have as much "baggage" with them. Because they are new at the game, one finds all kinds of new bureaucratic paperwork that one would not have expected from the federal government, but nothing in the world is free. The second advantage of state money to a departmental level, is that it is possible to buy large pieces of equipment fairly easily. In most cases, the state programs are oriented such that they want to improve their technology base in a local area. This tends to imply big pieces of capital equipment that could not be purchased on federally-funded programs. This is a tremendous advantage to a department in order to maintain a first-rate research program.

How is the economic development measured? There are basically five components to it. First, is technology transfer to major corporate sponsors. How this is done is a very tricky issue. In some cases, corporations are willing to place one of their scientists at the academic site in order to facilitate the transfer. However, this is another real cost to the corporation, resulting in an additional cost of sponsoring this work over another $\$ 100,000$ per year. Many corporations are not willing to do that. While you may be able to get $\$ 50,000$ to $\$ 100,000$ as a sponsor of a center, it is quite another matter to get a scientist whose loaded salary is on the order of $\$ 100,000$ to $\$ 150,000$ per year to be allocated to the center. However, if one is serious about technology transfer, it is an absolute must, in order to maintain a center over an extended period of time. The second reason is that it is difficult to get people to come as it does not appear to be in the best interests of the individual scientist. Unlike winning a Sloan Fellowship to attend MIT, which clearly indicates that person is on the way up the corporate ladder, it is not clear how it is viewed when a scientist takes a year off to go to a university to do technology transfer. 
The second part of economic development is small business formation. What role universities should play in facilitating that is less obvious. Clearly, if you want to maintain state money, you have to help out in this. At Rochester, we are teaching a course called Optical Entrepreneurship. The syllabus of that course is shown in Figure 4. This course is not without controversy; however, my colleagues in The Institute of Optics felt that since it was not an optics course, we should not be teaching it, and the Simon School people (our business school) felt that it was too technology oriented and not enough business oriented. I, however, personally believe that these types of courses are very important, not only for students to learn about small business formation, but also to learn more about how things are done in the corporate world. As part of the course, they were required to write a business plan on some part of research they were conducting in their laboratory, and to present these business plans before a "Venture Capital Board" to raise funds. Many students learned the difficulty of transitioning research from the academic laboratories to a product. I think if they have learned nothing else, that was a valuable lesson.

A third part of economic development is patent licensing. Universities, by and large, are naive in their use of patents. Faculty members consider patents to be, at best, a waste of time, and are normally unwilling to even consider the problem of filing. This represents a serious problem. If we want to be involved with the corporate world, we must have faculty members and students realize that patents are in their interest. Without the patent, it will be very difficult to continue corporate sponsorship. Further, educating administrators within universities about patent licensing is extremely important. There tends to be a philosophy of, "well, we'll just let this be done by someone in research administration." While this may be great on-the-job training, it is creating a very bad impression with corporations. Corporations expect to be negotiating patents by a set of rules that they have established between corporations. Dealing with university people is often very difficult. Further, the university people know nothing about the background of patent licensing, and one finds that university people tend to give out on issues they should not and become sticklers on problems about which they shouldn't even be worried. While some universities have now gone to centralized organizations, such as Research Corporations to handle their patent licensing, not all faculty members are very happy about it. If you want to have faculty members involved in the patent process, they should be happy with the way they are being administered.

The fourth area of economic development is increasing human resource base. have already made a case that the number of students who want to enter the optics field particularly justifies expanded programs. It is our students who are our most important product from universities. They are the people that will be contributing to the body of the science in the year 2010 and we should not under-estimate this. The final area of economic development is education. I have alluded to this in a number of ways and I am simply not meaning education in the sense of classroom education. Education is one of understanding what each of the major components of our society is. How will the industrial world, the academic world, and the governmental world 
interact. The big problems of our society in the next twenty years are going to be based on science. It is important that every student that goes through our universities be educated in some of the fundamental problems of our society. Equally important is that we must make sure that industry understands the roles of the university are for the long-term. We measure our successes in decades, and industry measures their successes in quarters. This represents a huge gap that we must overcome. One of the purposes of this meeting is to help overcome that gap.

\section{EXPECTATIONS AND MOTIVATIONS}

While the title of this section is somewhat strange, I believe it is an appropriate one. Most people are happy when their expectations are realized and understanding the expectations of the individual components is extremely important. There are two parts to this. The first is the expectations of the university professors and the second is the expectations of the industrial sponsors. The university professors, on the extreme, would prefer to have no rules, i.e., whatever they do is publishable. If changes occur in their research directions, they simply go along those paths. A less extreme example would be that most faculty members would accept the rules of the federal government. While they may not be happy with them, at least they understand them. This involves the right to publish, includes the patent rights which are assigned to the university or the inventors, and in many situations, they do have the freedom to change course in mid-contract to follow new leads, as long as the general topic is the same. This is particularly true with NSF and ARO funding, and less so in more direct researches as those coming out of the various DoD commands. We must remember that the motivation for a person to become a university professor, by and large, is to do fundamental research without regard to its application. While many of us as individuals may be very interested in applications and in the developmental aspects of research, we have to recognize that many of our colleagues do not share our views.

The expectations of industrial sponsors, on the extreme, is that the companies would use the same rules as they use for employees, i.e., they have the right to refuse publication or travel to meetings, the patent rights are all owned by the corporation, and changes in directions occur at the decision of the "company." In this case, we have to remember the motivation of research by the corporation is to lead to profit. I do not want to make it sound as if I am doing a "Michael Douglas from Wall Street," but if the research is not contributing to a better product, a cheaper product, and more sales, then it is generally of no interest to the corporation. The time frame for making the decision may be different at different corporations. In a small business, the decisions are made over a relatively short number of years. A major corporation may be willing to carry some research for a decade before it is eliminated, but ultimately, how the research contributes to the profit and loss statement is a deciding factor. Again, as educators, we do not tend to appreciate that. I find that when students go out into the real world, after they have been doing "research for the sake of research", sometimes have a culture shock when they realize that research must be "relevant." 
Education of companies and academics about the roles and expectations and motivations of the other are extremely important.

\section{FORMAT FOR INDUSTRIALACADEMIC INTERACTION}

I have broken the interactions down into four major methods. These are: industrial associates or affiliates programs, sponsored research, centers and teaming arrangements. The most common interaction is called industrial associates or affiliates programs. In these cases, each member company gives between $\$ 5,000$ and $\$ 15,000$ per year to support university departmental activities. The typical uses of this money are to do faculty development and to provide for student support. The companies motivation for participating in these programs vary depending upon the orientation of individuals within companies. The typical motivations are philanthropic, recruiting, technology transfer, interaction with faculty and interaction with other companies. Since the meetings that are held in association with these affiliates programs bring together industrial people, students and faculty, the opportunity for technology transfer is fairly great. The opportunity for companies to meet in informal ways is somewhat enhanced since the typical person attending these meetings tend to be at the same level; first or second level managers. Recruiting is a strong motivation for some companies, as the cost of these programs is insignificant compared to their recruiting budget. It provides the companies with a headstart on recruiting at all levels. For doctoral students, the companies may track a student to find the one they really want over the long-term. The ability to call faculty members and obtain a reliable recommendation on a student or on some piece of research is not an insignificant part of the programs. However, no matter how good these programs may be, the bottom line is that it is unlikely that more than $\$ 150,000$ to $\$ 300,000$ per year can be generated. This would only be in the case where established programs exist with a strong student body. Remember, students are the most important product of these programs. Other than the few companies that are philanthropic, they are really looking for the technology that the students are generating, or for the students to go to work for them.

The second method is that of sponsored research. Typically, these are contracts that run between $\$ 30,000$ and $\$ 100,000$ per year and typically are set up between an individual faculty member and a corporate researcher. The scope of work is established between the two, and is often based on an individual professional friendship that has developed between the two. The corporate researcher has a responsibility to make sure that the money is spent well. Anytime money is spent outside the corporate environment, some manager wants to know why that is being done and why it is not being done internally. Most companies use this as a way to look at the periphery of their main vision system. Of course, most companies have, or we hope they have, a strong direction, but also recognize that something may be coming from the corners that may affect their business in a significant way. University research provides a method for doing that. One of the difficulties of these programs is they tend to be one to three years, with a tendency to be on the shorter end rather than 
the longer end. There is considerable pressure on the corporate side to show results and this concept is not easy to do with Ph.D. dissertations. This again is an important area of research, but in terms of The Institute of Optics, probably does not represent more than $\$ 200,000$ of total research base.

The new vogue thing are called "Centers," and I like to refer to them as "Centers for Left Handed Optics". These are centers that are usually established with a fee of $\$ 50,000$ to $\$ 300,000$ per year per member with goals that are measured in timeframes of three to five years. Most often they are in response to the inquiries of one or two industries to a department saying, "would you be interested in 'left-handed' optics." If enough money is waved in front of the right administrators, then of course we are interested in left-handed optics. How could we not be interested in left-handed optics, and so a center is established. The cash flow is usually fantastic. It is not hard to develop centers that are run on $\$ 2,000,000$ budgets a year. The university is happy because the centers are generating more overhead rate, the faculty is happy because they are able to get state-of-the-art equipment, the return on investment for the corporate sponsors of these centers can be very large because their money is being highly leveraged and, therefore, it is easy to sell it to the MBA mentality. What are the dangers of such centers? One, is that they tend to be micro-managed. Each corporate sponsor, and the more you have, the more difficult it becomes, wants the research to be directed in their way. I was involved as a consultant to the consortium at Battelle, which is not unlike these centers that are being sponsored at universities. Being an outsider to the whole program, I watched how each company tried to pull the strings of the director to try to get certain work done. What happens, of course, is that some companies are unhappy. If they are unhappy to some degree, they pull their funding. When one company starts pulling out, it is very important to make sure that a domino effect does not occur. Changes in management of the companies can also have a very negative effect, (or a positive effect), on centers, as the program will be viewed as that of the predecessor. When one deals with matching funds from corporations and state, one is under constant pressure to try to walk a path between the interests of all of them. One can argue that they are all equally unhappy, then you are probably doing the right thing. One would prefer to be in the situation where they are all happy, but that is not always possible. I believe that one of the biggest dangers of centers is that too much of the intellectual capacity of the United States that is embodied in faculty members is going into research that has only a three to five year goal. The traditional role at universities has been to look at decades. As more and more of our research base is used to do short-term goals, then the technology base of the United States will be seriously eroded at the beginning of the next century.

The final type of arrangement with the university and industrial community is that of teaming arrangements. There seems to be more interest on the part of university, federal and corporate people to create a teaming arrangement where the universities do the fundamental research and provide technical support to major contract programs. The federal government is certainly encouraging these. This has the opportunity of defining fundamental research tasks at the beginning that need to be accomplished, and if they succeed, would have dramatic effects of the program. The 
corporation, on the other hand, can look at the normal paths and use existing technology to solve the problem. The university tries to establish a whole new route that will make the problem go away, or lead to a technology advancement, that will significantly change the way the problem is approached. This type of arrangement can, if properly organized, preserve the long-term research needs of the universities, while still providing sufficient funds to allow for both tasks to be followed.

\section{DANGERS}

The fundamental question is, how much influence should industry have over university research? Or, to put it another way, how should the short-term goals of industry (the profit and loss each quarter) and the MBA mentality have over what we do to develop a technological base for the 21st century? How is relevant research to be defined? Who decides what relevant research is? I have noticed in my interactions with different industries, what one industry considers to be extremely relevant, the industrial representative from the second company considers to be totally irrelevant for their corporate needs. What is in the best interest for the long-term? Should a university try to form a center for left-handed optics? While there will be incredible pressure to do that on everybody's part, is it really in the national best interest? If there are no other sources of funds, at what point do we sell our soul? We obviously would like to hold out for as much freedom as we possibly can, but the reality of the world is such that if we are going to run a first-rate university and a first-rate research program, we need a considerable amount of cash flow. If US industry is not willing to pick up the tab for this, how should we deal with our foreign industrial sponsors? While the role of foreign companies has not been a part of this paper, it is not one to be overlooked. When considering the ratio of the dollar to the yen today, the cost of doing research in the United States is significantly lower than it was before. Countries with a tremendous trade surplus can use some money from their US operations in a very effective way while gaining access to the technology for the 21st century. How should the roles of engineering and fundamental physics be traded off? Again, we have not discussed this, but it is something that should be worried about for the future. It is my opinion that the academic departments, as we currently know them, probably cannot survive for more than two more decades. Their costs will be such, and the need to be relevant will be so great, that most departments will have to make incredible concessions to their sponsors. What will be the form of an engineer in the year 2010? I consider that to be a very interesting question, and one that we should be discussing in more detail. What type of a person should we be educating in 1990 and the year 2010? What type of background should they have? How do we assure that the Ph.D.s that are generated 20 years from now will be able to contribute to the body of knowledge 30 years after. 
Finally, while I have been fairly negative in many of my comments about the dangers of industrial and federal sponsorship, I believe that it is an incredible advantage. As we work through some of these problems, and as long as we are aware of the problems, we can create a competitive advantage I believe second to none. This is an opportunity, but not without some pitfalls, but one that I believe we must seize and we must work together with the universities, the industrial community and the governmental agencies to create a better technology base for the year 2010 . 